\title{
A method for distinguishing and linking turbulent entrainment mixing and collision-coalescence in stratocumulus clouds
}

\author{
LU ChunSong ${ }^{1,2 *}$, LIU YanGang ${ }^{2} \&$ NIU ShengJie ${ }^{1}$ \\ ${ }^{1}$ Key Laboratory for Atmospheric Physics and Environment of China Meteorological Administration, Key Laboratory of Meteorological Disaster \\ of Ministry of Education, Nanjing University of Information Science and Technology, Nanjing 210044, China; \\ ${ }^{2}$ Atmospheric Sciences Division, Brookhaven National Laboratory, New York 11973, USA
}

Received August 10, 2012; accepted September 28, 2012; published online December 19, 2012

This paper presents a method to distinguish and link inhomogeneous mixing with subsequent ascent and collision-coalescence. Three stratocumulus clouds analyzed were collected over the U.S. Department of Energy's Atmospheric Radiation Measurement Southern Great Plains site during the March 2000 cloud Intensive Observation Period. The criteria are presented to distinguish the two processes. Inhomogeneous mixing with subsequent ascent is identified if cloud along an aircraft horizontal leg is non-drizzling and the relationship between cloud volume-mean radius and liquid water content is negative; in contrast, drizzling and positive relationship between the above two properties are the criteria for collision-coalescence. To link the two processes, threshold function, the possibility of occurrence of collision-coalescence, is employed; the big droplets generated during the inhomogeneous mixing with subsequent ascent increase the threshold function, initiates collision-coalescence and produces drizzle drops. To the authors' knowledge, this is the first study on distinguishing and linking inhomogeneous mixing with subsequent ascent and collision-coalescence based on observational data.

entrainment-mixing process, collision-coalescence, stratocumulus, warm rain initiation, drizzle

Citation: Lu C S, Liu Y G, Niu S J. A method for distinguishing and linking turbulent entrainment mixing and collision-coalescence in stratocumulus clouds. Chin Sci Bull, 2013, 58: 545-551, doi: 10.1007/s11434-012-5556-6

Warm rain initiation has been a central topic of cloud physics for a long time [1-3]. Although cloud droplets are initially produced by condensation of water vapor on cloud condensation nuclei, condensation alone can not produce droplets large enough to initiate collision-coalescence; regarding warm rain initiation, discrepancy exists between theories and observations. First, the spectra generated by condensation are much narrow because condensation rate is negatively correlated with droplet size [4,5]. In contrast to the theoretical spectra, the observational ones are much wider [6]. The instrument could introduce some broadness of spectra [7,8]; however, even if the spectral broadening due to instrumental artifacts is taken into account, the narrowest spectra in the cumulus are still broader than the calculated spectra in adiabatic growth [9]. Second, the time

*Corresponding author (email: luchunsong110@gmail.com) needed for warm rain initiation from theoretical calculation is much longer than that needed in reality based on observations [10]. Third, the standard deviation of spectra generally increases or keeps nearly constant with height, whereas in adiabatic theory, standard deviation should decrease with height [11]. Fourth, cloud does not need the depth predicted in adiabatic theory to produce drizzle drops. Herckes et al. [12] observed a warm shallow fog with height less than 100 $\mathrm{m}$ was drizzling.

Several mechanisms have been advanced to explain the discrepancy between observations and theories [13], such as fluctuation of supersaturation field [14,15], enhanced collision kernel due to turbulence [16,17], and the role of giant or ultragiant cloud condensation nuclei $[18,19]$. Another common and likely mechanism is through entrainment of subsaturated environmental air and subsequent mixing [20-24]. Over the last few decades, great efforts have been 
devoted to understanding the effect of entrainment mixing on cloud microphysical properties through observations and modeling. The homogeneous [25,26] and inhomogeneous entrainment-mixing processes [26-28] have been explored in detail. Theoretically, inhomogeneous mixing with subsequent ascent can produce large droplets which are important for the collision-coalescence process; these two processes are closely connected, and collision-coalescence could be seen as a continuum of inhomogeneous mixing with subsequent ascent [29]. Distinguishing and linking the two processes from observational data are critical to understand the effect of entrainment mixing on warm rain initiation. But such studies are lacking. This study presents a method to distinguish them mainly through cloud microphysical relationships and link them with autoconversion threshold function $(T)$ proposed by Liu et al. [30,31] using aircraft in situ observations of stratocumulus clouds. To the authors' knowledge, this is the first time to distinguish and link them based on observational data.

\section{Description of cloud IOP and data}

The cloud Intensive Observation Period (IOP) was conducted by the Atmospheric Radiation Measurement Research Facility at the Southern Great Plains site during 1-26 March 2000, and aimed at documenting mid-latitude cloud properties for evaluating models and retrieval algorithms. Of particular relevance to this work are the 12 flights taken with the Cessna Citation research aircraft of the University of North Dakota. Cloud and drizzle size distributions were measured with a Particle Measuring Systems (PMS) Forward Scattering Spectrometer Probe (FSSP-100) and an optical array probe (1D-C), respectively. The FSSP probe sizes and counts cloud droplets in 15 bins, with bin centers from 2.7 to $30 \mu \mathrm{m}$ in radius; the $1 \mathrm{D}-\mathrm{C}$ probe has 30 bins with bin centers from 12 to $300 \mu \mathrm{m}$ in radius. Measurements of both instruments are corrected with standard procedures [32-35]. The aircraft was also mounted with a Cloud Particle Imager (CPI) manufactured by the Stratton Park Engineering Company; images of cloud particles collected with CPI are used, together with air temperature, to ascertain the clouds analyzed are liquid-water clouds. Air temperature was measured with Rosemount Model 102 probe. The $1 \mathrm{~Hz}$ data are used in this study.

The key cloud microphysical properties used in this study, including liquid water content (LWC), droplet number concentration $(N)$, and volume-mean radius $\left(r_{\mathrm{v}}\right)$, are calculated from the FSSP-measured droplet size distributions; the last two bins (radius $>26 \mu \mathrm{m}$ ) are not included because the drops whose radii are larger than $25 \mu \mathrm{m}$ are considered to be drizzle drops. A cloud record is defined by the criteria of $N>10 \mathrm{~cm}^{-3}$ and LWC $>0.001 \mathrm{~g} \mathrm{~m}^{-3}$ [36,37]. Both thresholds for $N$ and LWC are introduced to eliminate the measured size distributions that are probably composed of large aerosols instead of cloud droplets.

The 1D-C measurements are mainly used for determining whether or not a flight leg was drizzling; the first two bins (radius $<27 \mu \mathrm{m}$ ) are not used. A leg was considered as drizzling if drizzle liquid water content was larger than 0.005 $\mathrm{g} \mathrm{m}^{-3}$; drizzling legs were further divided into heavily drizzling and lightly drizzling by drizzle liquid water content of $0.1 \mathrm{~g} \mathrm{~m}^{-3}$.

A total of 12 cases were measured during the cloud IOP, including stratocumulus, altocumulus, and cirrus. Lu et al. [38] focused on the five warm stratocumulus cases that either had cloud-top temperature above zero degree Celsius or no ice crystals based on the CPI particle images (these ice-free clouds are referred to as warm clouds); they studied the dominant entrainment-mixing mechanisms. To further study the effect of mixing process and initiation of warm rain, this study will focus on both drizzling and non-drizzling legs in the three drizzling clouds (17, 18, 21 March 2000) among the five warm stratocumulus cases. A total of 12 horizontal flight legs that satisfy these conditions are identified in the three cases: 6 in the 17 March 2000 case, 3 in the 18 March 2000 case and 3 in the 21 March 2000 case.

\section{Results}

As in the work by Lu et al. [38], this study also analyzes entrainment-mixing processes in the framework of homogeneous/inhomogeneous entrainment-mixing model [29,39]; according to this framework, mixing processes can be classified into three major types. First, in homogeneous mixing, all cloud droplets are exposed to the same environmental conditions and evaporate at the same time; $r_{\mathrm{v}}$ and $N$ are anticipated to be positively correlated. Second, in extreme inhomogeneous mixing, droplets surrounding an entrained dry air parcel evaporate to saturate the parcel and then mixing between this parcel and the remaining part of cloud dilutes the cloud; as a result, $r_{\mathrm{v}}$ changes slightly as $N$ decreases. The third mechanism is inhomogeneous mixing with subsequent ascent whereby a diluted parcel after extreme inhomogeneous mixing process is lifted upward, and the big droplets in the diluted parcel can grow faster than those in undiluted parcels; thus $r_{\mathrm{v}}$ is negatively correlated with $N$.

Similar to inhomogeneous mixing with subsequent ascent, $r_{\mathrm{v}}$ and $N$ in collision-coalescence are expected to be negatively correlated because the growth of big droplets consumes small ones [30]. Therefore, to distinguish these two processes, other criteria are needed. First, drizzling is the direct result of collision-coalescence; thus drizzling indicates the occurrence of collision-coalescence. Second, the relationship between $r_{\mathrm{v}}$ and LWC has a different behavior in these two processes. During the inhomogeneous mixing with subsequent ascent, $r_{\mathrm{v}}$ vs. LWC is expected to be negatively correlated, because droplets in a diluted parcel grow faster and bigger [11,21,40,41]. However, the continuous 
collision-coalescence model shows that $\mathrm{d} r_{\mathrm{v}} / \mathrm{d} t \propto \mathrm{LWC}$ [42], i.e. a parcel with larger LWC tends to have larger $r_{\mathrm{v}}$; thus $r_{\mathrm{v}}$ vs. LWC is generally expected to be positive at an early stage of collision-coalescence. At a late stage, the big droplets produced during collision-coalescence might be beyond $25 \mu \mathrm{m}$ in radius, which are not counted in the calculations of $N$, LWC and $r_{\mathrm{v}}$; as a result, both LWC and $r_{\mathrm{v}}$ might decrease; then the negative relationship of $r_{\mathrm{v}}$ vs. $N$ and the positive relationship of $r_{\mathrm{v}}$ vs. LWC could be destroyed. That's the reason to divide drizzling legs into lightly drizzling (the early stage) and heavily drizzling (the late stage).

Based on the above criteria, 8 out of 12 horizontal legs are identified as affected by collision-coalescence because they had drizzle amount larger than $0.005 \mathrm{~g} \mathrm{~m}^{-3}$ and the relationships of $r_{\mathrm{v}}$ vs. LWC were positive (Figure 1(a)). The reason to use the slopes of the relationships in Figure 1 instead of correlation coefficients will be discussed later. Different from the legs affected by collision-coalescence, the non-drizzling leg affected by inhomogeneous mixing with subsequent ascent had a negative relationship of $r_{\mathrm{v}}$ vs. LWC. As expected, the relationships of $r_{\mathrm{v}}$ vs. $N$ were all negative along the legs affected by inhomogeneous mixing with subsequent ascent and collision-coalescence (Figure 1(b)). To be specific, Figure 2 further shows the scatter plots of the relationships of $r_{\mathrm{v}}$ vs. $N$ and $r_{\mathrm{v}}$ vs. LWC along Leg 3 in the 18 March 2000 case (affected by inhomogeneous mixing with subsequent ascent) and along Leg 2 in the 17 March 2000 case (affected by collision-coalescence). In

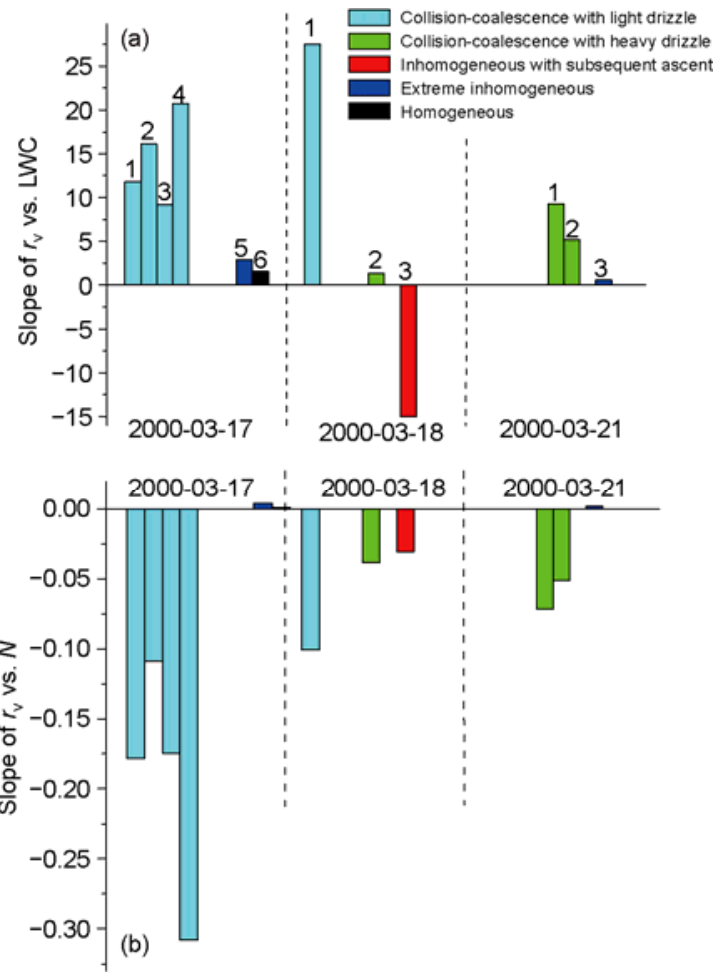

Figure 1 Bar plots for (a) the slopes of volume-mean radius $\left(r_{\mathrm{v}}\right)$ vs. liquid water content (LWC) and (b) the slopes of $r_{\mathrm{v}}$ vs. cloud droplet number concentration $(N)$ dominantly affected by different processes along different legs in the three cases. The numbers in the figures are horizontal leg numbers.
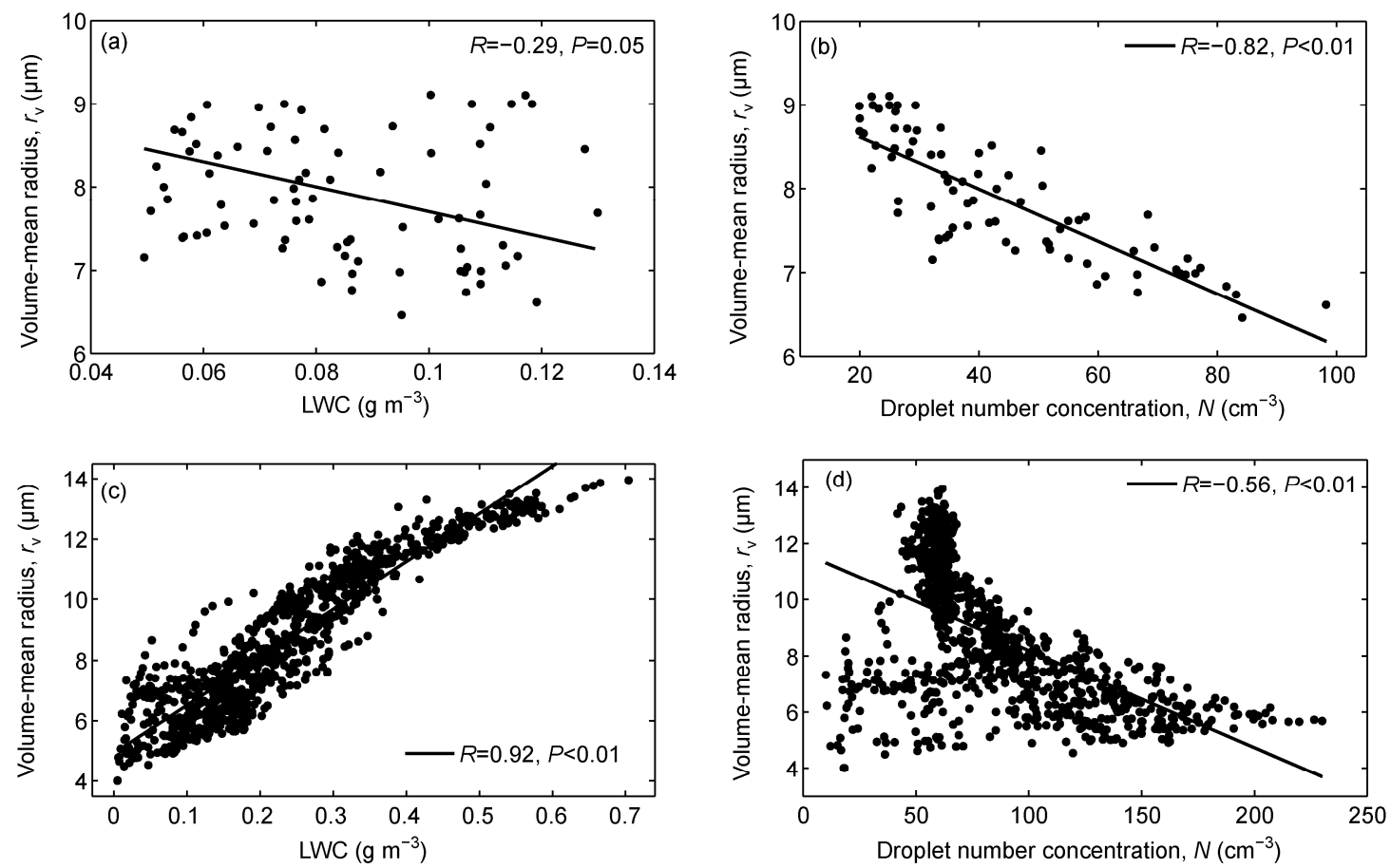

Figure 2 (a) Relationship between cloud volume-mean radius ( $\left.r_{\mathrm{v}}\right)$ and liquid water content (LWC) and (b) relationship between $r_{\mathrm{v}}$ and droplet number concentration $(N)$ along Leg 3 in the 18 March 2000 case. (c) and (d) are, respectively, the same as in (a) and (b) but for Leg 2 in the 17 March 2000 case. $R$, Correlation coefficients; $P, P$-value for the correlations. 
addition, the other three non-drizzling legs affected by homogeneous or extreme inhomogeneous mixing are also shown in Figure 1; all the slopes of their microphysical relationships were small (see detailed analysis in the work by Lu et al. [38]).

Another interesting characteristic is that the slopes of $r_{\mathrm{v}}$ vs. $N$ (absolute values) and $r_{\mathrm{v}}$ vs. LWC along the three heavily drizzling legs were smaller than those along the five lightly drizzling legs; the heavily drizzling leg in the 18 March 2000 case had the smallest slopes (Figure 1). Thus $r_{\mathrm{v}}$ increases faster with decreasing $N$ or increasing LWC along lightly drizzling legs than along heavily drizzling legs, reflecting the effects of collision-coalescence with different intensities on cloud microphysics. Slopes of the relationships can reflect this phenomenon but correlation coefficients cannot. That is the reason why the slopes are used here. Collision-coalescence with different intensities affected the microphysical relationships by moving cloud water to drizzle water; but the signs of the relationships remained. One possible reason was that the effect of moving cloud water to drizzle water was not significant enough to completely destroy the microphysical relationships; another possible reason was that when collision-coalescence moved liquid water from cloud water to drizzle water, condensation might occur at the same time, compensating the cloud water loss due to collision-coalescence; a drizzling cloud was a factory of drizzle and compensating cloud water through condensation was necessary to continual drizzle production.

The above discussion shows a method to distinguish in- homogeneous mixing with subsequent ascent and collisioncoalescence; in fact, the two processes are closely connected [29]. To link the two processes, autoconversion threshold function $(T)$, proposed by Liu et al. [30,31] is used. The expression of $T$ can be generally described by

$$
T=\left[\frac{\int_{r_{\mathrm{c}}}^{\infty} r^{6} n(r) \mathrm{d} r}{\int_{0}^{\infty} r^{6} n(r) \mathrm{d} r}\right]\left[\frac{\int_{r_{\mathrm{c}}}^{\infty} r^{3} n(r) \mathrm{d} r}{\int_{0}^{\infty} r^{3} n(r) \mathrm{d} r}\right],
$$

where $r$ is droplet radius, $n(r)$ is cloud droplet size distribution, and $r_{\mathrm{c}}$ is critical radius for autoconverstion. Liu et al. [43] derived an analytical expression for predicting $r_{\mathrm{c}}$ in the autoconversion parameterization:

$$
r_{\mathrm{c}} \approx 4.09 \times 10^{-4} \beta_{\mathrm{con}}^{1 / 6} \frac{N^{1 / 6}}{\mathrm{LWC}^{1 / 3}},
$$

where $\beta_{\mathrm{con}}=1.15 \times 10^{23}$ is an empirical coefficient

The value of $T$ is a measure of the possibility of collision-coalescence process, ranging from no action $(T=0)$ to full action $(T=1)$. As an example, Figure 3 shows the relationships between $r_{\mathrm{v}}$ and $N$ and between $r_{\mathrm{v}}$ and LWC with different $T$ ranges along Leg 3 in the 18 March 2000 case (affected by inhomogeneous mixing with subsequent ascent) and Leg 2 in the 17 March 2000 case (affected by collisioncoalescence).
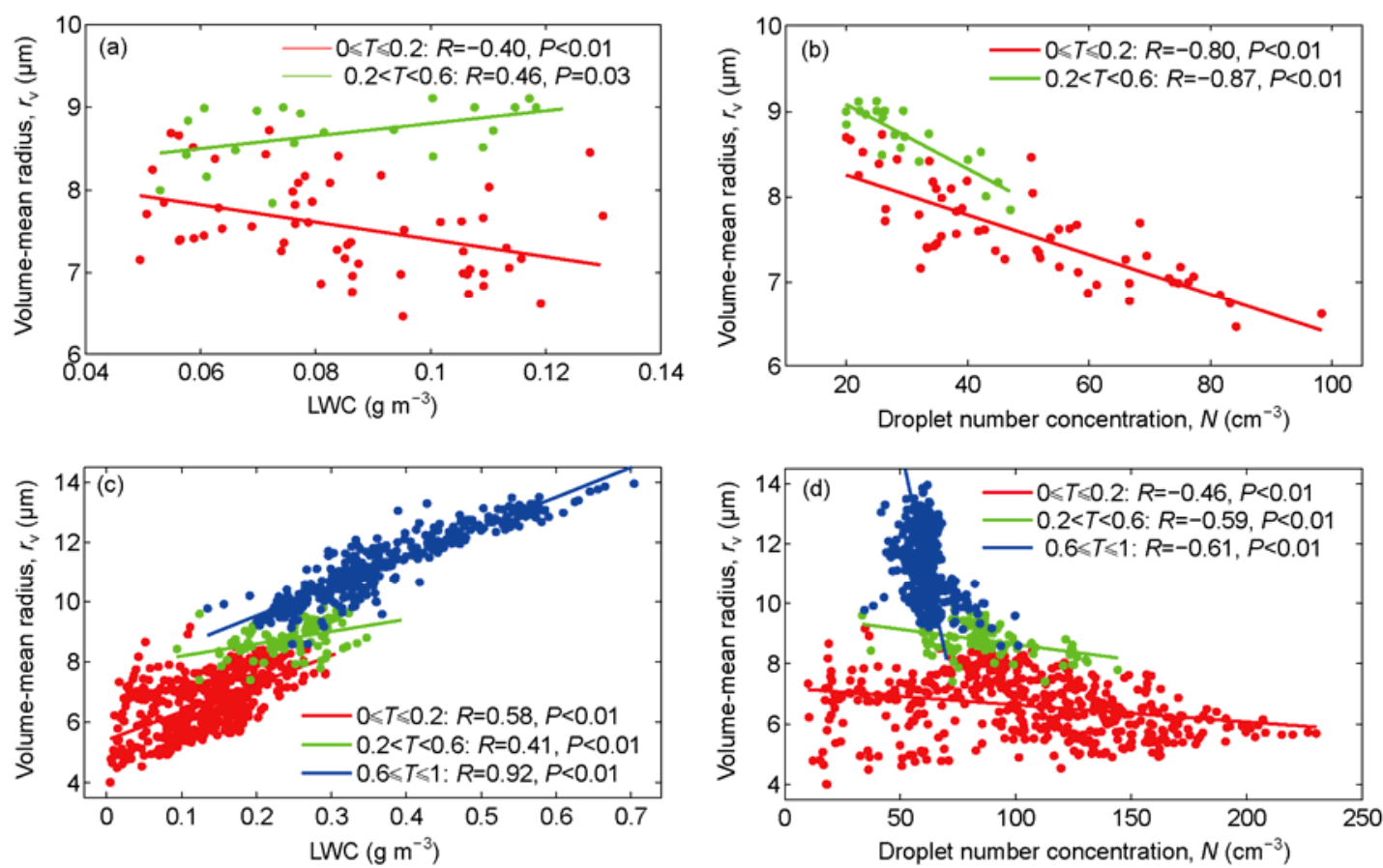

Figure 3 (a) Relationship between cloud volume-mean radius $\left(r_{\mathrm{v}}\right)$ and liquid water content (LWC) and (b) relationship between $r_{\mathrm{v}}$ and droplet number concentration $(N)$ in different threshold function $(T)$ ranges along Leg 3 in the 18 March 2000 case. (c) and (d) Same as in (a) and (b) but for Leg 2 in the 17 March 2000 case. $R$, Correlation coefficients; $P, P$-value for the correlations. 
The values of $T$ along Leg 3 in the 18 March 2000 case were smaller than 0.6, whereas along Leg 2 in the 17 March 2000 case, $T$ was larger than 0.6 . Both the relationships of $r_{\mathrm{v}}$ vs. $N$ along these two legs were negative. As to $r_{\mathrm{v}}$ vs. LWC, Leg 2 in the 17 March 2000 case had a positive correlation. Along Leg 2 in the 18 March 2000 case, this relationship was negative for $0 \leqslant T \leqslant 0.2$, but positive for $0.2<T<0.6$; that is to say, some big droplets produced during inhomogeneous mixing with subsequent ascent $(0 \leqslant T \leqslant 0.2)$ increase $T$ and already initiated collision-coalescence to some extent $(0.2<T<0.6)$. The importance of inhomogeneous mixing for warm rain initiation is consistent with previous studies. For example, Lasher-Trapp et al. [21] found that larger droplets were more prominent when the mixing process was assumed to be inhomogeneous than homogeneous. In contrast, Yum and Hudson [44] found that there were no larger droplets in diluted cloud parcels when clouds were affected by homogeneous mixing; then they pointed out that homogeneous mixing did not promote droplet growth.

It is noteworthy that when $T<0.2$, collision-coalescence was relatively weak and other processes might occur at the same time. For example, in Figure 3(c) and (d), some data points had $r_{\mathrm{v}}<7 \mu \mathrm{m}, \mathrm{LWC}<0.1 \mathrm{~g} \mathrm{~m}^{-3}$ and $N<80 \mathrm{~cm}^{-3}$. This could be caused by evaporation of big droplets or secondary nucleation of entrained cloud condensation nuclei and subsequent condensation. The relationships of $r_{\mathrm{v}}$ vs. $N$ were even weakly positive with $T<0.2$ along some other legs affected by collision-coalescence, but the relationships of $r_{\mathrm{v}}$ vs. LWC were always positive. In general, the relationships of $r_{\mathrm{v}}$ vs. $N$ and $r_{\mathrm{v}}$ vs. LWC along other legs affected by collision-coalescence were similar to Figure 3(c) and (d).

As mentioned above, only one leg was affected by inhomogeneous mixing with subsequent ascent and much more legs (eight) were affected by collision-coalescence; the reason could be that collision-coalescence occurred quickly as long as big droplets were produced in inhomogeneous mixing with subsequent ascent, because the rate of collision-coalescence increased rapidly with droplet size [45]. The occurrence of collision-coalescence caused drizzling and a positive relationship of $r_{\mathrm{v}}$ vs. LWC, hiding the signal of inhomogeneous mixing with subsequent ascent. It is difficult to capture the transition state in reality. In addition, inhomogeneous mixing (three legs) dominated over homogeneous mixing (one leg) along non-drizzling legs. Even along the leg dominantly affected by homogeneous mixing, inhomogeneous mixing also occurred [38]. In the further ascent and growth after inhomogeneous mixing, big droplets were produced in diluted parcels; these big droplets initiated collision-coalescence and produced drizzle drops.

\section{Concluding remarks}

A method to distinguish and link inhomogeneous mixing with subsequent ascent and collision-coalescence is pre- sented with aircraft observations. Data along twelve aircraft horizontal legs in three drizzling stratocumulus cases are analyzed. Four legs were non-drizzling, three were lightly drizzling and the other five were heavily drizzling.

The relationship between cloud droplet volume-mean radius $\left(r_{\mathrm{v}}\right)$ and number concentration $(N)$ is negative both in the inhomogeneous mixing with subsequent ascent and collision-coalescence. Other criteria are needed to distinguish the two processes. One criterion for collision-coalescence is drizzling because drizzling is the result of collision-coalescence. The other criterion is a positive relationship between $r_{\mathrm{v}}$ and cloud liquid water content (LWC) because collision-coalescence is more vigorous when LWC is larger, which produces larger $r_{\mathrm{v}}$; whereas the relationship of $r_{\mathrm{v}} \mathrm{vs}$. LWC is negative during inhomogeneous mixing with subsequent ascent. The eight drizzling legs had all positive relationships of $r_{\mathrm{v}}$ vs. LWC, thus they were affected by collision-coalescence. The three heavily drizzling legs had smaller slopes of $r_{\mathrm{v}}$ vs. $N$ (absolute values) and $r_{\mathrm{v}}$ vs. LWC than the five lightly drizzling legs, because collision-coalescence moved more liquid water from cloud water to drizzle water along heavily drizzling legs, tending to destroy the negative $r_{\mathrm{v}}$ vs. $N$ and positive $r_{\mathrm{v}}$ vs. LWC. But still the signs of the two relationships remained; the reason could be that the effect of moving cloud water to drizzle water was not significant enough or condensation occurred at the same time, which compensated the cloud water loss due to collision-coalescence.

The link of inhomogeneous mixing with subsequent ascent and collision-coalescence is based on threshold function $(T)$, the possibility of occurrence of collision-coalescence. The slope of $r_{\mathrm{v}}$ vs. LWC was positive for the legs affected by collision-coalescence in different $T$ ranges. Whereas for the leg affected by inhomogeneous mixing with subsequent ascent, the slope of $r_{\mathrm{v}}$ vs. LWC was negative for $0 \leqslant T \leqslant 0.2$, but positive for $0.2<T<0.6$. The big droplets produced during inhomogeneous mixing with subsequent ascent initiated collision-coalescence when $0.2<T$ $<0.6$, causing a positive relationship of $r_{\mathrm{v}}$ vs. LWC. In addition, extreme inhomogeneous mixing dominated over homogeneous mixing along the four non-drizzling legs. So the three clouds were mainly affected by extreme inhomogeneous mixing; in the subsequent ascent, big droplets were produced and then initiated collision-coalescence. To the authors' knowledge, this is the first time to distinguish and link the two processes (entrainment mixing and collisioncoalescence) based on observational data.

Several points are noteworthy. First, this study examines entrainment-mixing processes in the framework of homogeneous/inhomogeneous mixing model, without considering other models, such as entity-type entrainment mixing [46,47] and circulation mixing [40]. Second, the method presented here is based on three continental stratocumulus clouds with $1 \mathrm{~Hz}$ data. More cloud types under different conditions (e.g. marine vs. continental) should be studied to test the method. 
High resolution measurements are necessary [28] due to the scale dependence of physical processes [48]. Third, homogeneous/inhomogeneous mixing is closely related to entrainment rate [25,49], and further affects collision-coalescence. A comprehensive understanding of these factors/ processes warrants further study. Fourth, aerosol affects both entrainment mixing process and collision-coalescence among other cloud physical processes, and further affects cloud microphysical properties [50-52], thus it is necessary to account for aerosol in the future study on distinguishing and linking entrainment mixing processes and collisioncoalescence.

We are grateful to Mike Poellot, Tony Grainger, and Andrea Neumann at the University of North Dakota for providing the data. Liu and Lu were supported by the U.S. Department of Energy (DOE) Earth System Modeling (ESM) Program via the FASTER Project (www.bnl.gov/esm) and Atmospheric System Research (ASR) Program. Niu was supported by the Qing- Lan Project for Cloud-Fog-Precipitation-Aerosol Study in Jiangsu Province, China and a Project Funded by the Priority Academic Program Development of Jiangsu Higher Education Institutions.

1 Koo C-C. Recent investigations in the theory of the formation of the cloud-drop spectra (in Chinese). Acta Meteorol Sin, 1962, 32: 267284

2 Zhou X. Statistical theory of microphysical mechanisms in warm cloud precipitation (in Chinese). Acta Meteorol Sin, 1963, 33: 97107

3 Devenish B J, Bartello P, Brenguier J L, et al. Droplet growth in warm turbulent clouds. Q J Roy Meteor Soc, 2012, 138: 1401-1429

4 Rogers R R, Yau M K. A Short Course in Cloud Physics. 3rd ed. Burlington, MA, USA: Butterworth Heinemann, 1989

5 Yum S. Cloud droplet spectral broadening in warm clouds: An observational and model study. Dissertation for the Doctoral Degree. Nevada: University of Nevada, 1998

6 Martin G M, Johnson D W, Spice A. The measurement and parameterization of effective radius of droplets in warm stratocumulus clouds. J Atmos Sci, 1994, 51: 1823-1842

7 Cerni T A. Determination of the size and concentration of cloud drops with an FSSP. J Appl Meteorol, 1983, 22: 1346-1355

8 Schmidt S, Lehmann K, Wendisch M. Minimizing instrumental broadening of the drop size distribution with the M-Fast-FSSP. J Atmos Ocean Tech, 2004, 21: 1855-1867

9 Brenguier J L, Chaumat L. Droplet spectra broadening in cumulus clouds. Part I: Broadening in adiabatic cores. J Atmos Sci, 2001, 58: 628-641

10 Laird N F, Ochs H T, Rauber R M, et al. Initial precipitation formation in warm Florida cumulus. J Atmos Sci, 2000, 57: 3740-3751

11 Lehmann K, Siebert H, Shaw R A. Homogeneous and inhomogeneous mixing in cumulus clouds: Dependence on local turbulence structure. J Atmos Sci, 2009, 66: 3641-3659

12 Herckes $\mathrm{P}$, Chang $\mathrm{H}$, Lee $\mathrm{T}$, et al. Air pollution processing by radiation fogs. Water Air Soil Pollut, 2007, 181: 65-75

13 Beard K V, Ochs H T. Warm-rain initiation: An overview of microphysical mechanisms. J Appl Meteorol, 1993, 32: 608-625

14 Vaillancourt P A, Yau M K, Bartello P, et al. Microscopic approach to cloud droplet growth by condensation. Part II: Turbulence, clustering, and condensational growth. J Atmos Sci, 2002, 59: 34213435

15 McGraw R, Liu Y. Brownian drift-diffusion model for evolution of droplet size distributions in turbulent clouds. Geophys Res Lett, 2006, 33: L03802

16 Wen C-S. The effects of the correlative time of the fluctuating force field on the random growth of cloud droplets. Sci Sin, 1966, 15:
870-879

17 Shaw R A. Particle-turbulence interactions in atmospheric clouds. Annu Rev Fluid Mech, 2003, 35: 183-227

18 Johnson D B. The role of giant and ultragiant aerosol particles in warm rain initiation. J Atmos Sci, 1982, 39: 448-460

19 Feingold G, Cotton W R, Kreidenweis S M, et al. The impact of giant cloud condensation nuclei on drizzle formation in stratocumulus: Implications for cloud radiative properties. J Atmos Sci, 1999, 56: 4100-4117

20 Andrejczuk M, Grabowski W W, Malinowski S P, et al. Numerical simulation of cloud-clear air interfacial mixing: Homogeneous versus inhomogeneous mixing. J Atmos Sci, 2009, 66: 2493-2500

21 Lasher-Trapp S G, Cooper W A, Blyth A M. Broadening of droplet size distributions from entrainment and mixing in a cumulus cloud. Q J Roy Meteor Soc, 2005, 131: 195-220

22 Krueger S, Su C, McMurtry P. Modeling entrainment and finescale mixing in cumulus clouds. J Atmos Sci, 1997, 54: 2697-2712

23 Wang X, Xue H, Fang W, et al. A study of shallow cumulus cloud droplet dispersion by large eddy simulations. Acta Meteorol Sin, 2011, 25: 166-175

24 Kumar B, Schumacher J, Shaw R. Cloud microphysical effects of turbulent mixing and entrainment. Theor Comp Fluid Dyn, 2012: $1-16$

25 Jensen J B, Baker M B. A simple model of droplet spectral evolution during turbulent mixing. J Atmos Sci, 1989, 46: 2812-2829

26 Burnet F, Brenguier J L. Observational study of the entrainmentmixing process in warm convective clouds. J Atmos Sci, 2007, 64: 1995-2011

27 Gerber H E, Frick G M, Jensen J B, et al. Entrainment, mixing, and microphysics in trade-wind cumulus. J Meteorol Soc Jpn, 2008, 86: 87-106

28 Haman K E, Malinowski S P, Kurowski M J, et al. Small scale mixing processes at the top of a marine stratocumulus-A case study. Q J Roy Meteor Soc, 2007, 133: 213-226

29 Baker M B, Corbin R G, Latham J. The influence of entrainment on the evolution of cloud droplet spectra: I. A model of inhomogeneous mixing. Q J Roy Meteor Soc, 1980, 106: 581-598

30 Liu Y, Daum P H, McGraw R. Size truncation effect, threshold behavior, and a new type of autoconversion parameterization. Geophys Res Lett, 2005, 32: L11811

31 Liu Y, Daum P H, McGraw R, et al. Generalized threshold function accounting for effect of relative dispersion on threshold behavior of autoconversion process. Geophys Res Lett, 2006, 33: L11804

32 Baumgardner D, Strapp W, Dye J. Evaluation of the forward scattering spectrometer probe. Part II: Corrections for coincidence and dead-time losses. J Atmos Ocean Tech, 1985, 2: 626-632

33 Dye J, Baumgardner D. Evaluation of the forward scattering spectrometer probe. Part I: Electronic and optical studies. J Atmos Ocean Tech, 1984, 1: 329-344

34 Baumgardner D, Spowart M. Evaluation of the forward scattering spectrometer probe. Part III: Time response and laser inhomogeneity limitations. J Atmos Ocean Tech, 1990, 7: 666-672

35 Baumgardner D. Corrections for the response times of particle measuring probes. In: American Meteorological Society, World Meteorological Organization, eds. Proceedings of the 6th Symposium on Meteorological Observations and Instrumentation. New Orleans, USA. 1987. 148-151

36 Deng Z, Zhao C, Zhang Q, et al. Statistical analysis of microphysical properties and the parameterization of effective radius of warm clouds in Beijing area. Atmos Res, 2009, 93: 888-896

37 Zhang Q, Quan J, Tie X, et al. Impact of aerosol particles on cloud formation: Aircraft measurements in China. Atmos Environ, 2011, 45 $665-672$

38 Lu C, Liu Y, Niu S. Examination of turbulent entrainment-mixing mechanisms using a combined approach. J Geophys Res, 2011, 116: D20207

39 Baker M B, Latham J. The evolution of droplet spectra and the rate of production of embryonic raindrops in small cumulus clouds. J Atmos Sci, 1979, 36: 1612-1615 
40 Wang J, Daum P H, Yum S S, et al. Observations of marine stratocumulus microphysics and implications for processes controlling droplet spectra: Results from the Marine Stratus/Stratocumulus Experiment. J Geophys Res, 2009, 114: D18210

41 Siebert H, Franke H, Lehmann K, et al. Probing finescale dynamics and microphysics of clouds with helicopter-borne measurements. B Am Meteorol Soc, 2006, 87: 1727-1738

42 Wallace J, Hobbs P. Atmospheric Science: An Introductory Survey. 2nd ed. California: Academic Press, 2006

43 Liu Y, Daum P H, McGraw R. An analytical expression for predicting the critical radius in the autoconversion parameterization. Geophys Res Lett, 2004, 31: L06121

44 Yum S S, Hudson J G. Microphysical relationships in warm clouds. Atmos Res, 2001, 57: 81-104

45 Salby M L. Fundamentals of Atmospheric Physics. New York: Academic Press, 1995

46 Telford J W. Clouds with turbulence: The role of entrainment. Atmos
Res, 1996, 40: 261-282

47 Telford J W, Chai S K. A new aspect of condensation theory. Pure Appl Geophys, 1980, 118: 720-742

48 Liu Y, Hallett J. On size distributions of cloud droplets growing by condensation: A new conceptual model. J Atmos Sci, 1998, 55: 527536

49 Lu C, Liu Y, Yum S S, et al. A new approach for estimating entrainment rate in cumulus clouds. Geophys Res Lett, 2012, 39: L04802

50 Yu X, Dai J, Lei H, et al. Physical effect of cloud seeding revealed by NOAA satellite imagery. Chin Sci Bull, 2005, 50: 44-51

51 Lu G X, Guo X L. Distribution and origin of aerosol and its transform relationship with $\mathrm{CCN}$ derived from the spring multi-aircraft measurements of Beijing Cloud Experiment (BCE). Chin Sci Bull, 2012, 57: 2460-2469

52 Xue H, Feingold G, Stevens B. Aerosol effects on clouds, precipitation, and the organization of shallow cumulus convection. J Atmos Sci, 2008, 65: 392-406

Open Access This article is distributed under the terms of the Creative Commons Attribution License which permits any use, distribution, and reproduction in any medium, provided the original author(s) and source are credited. 